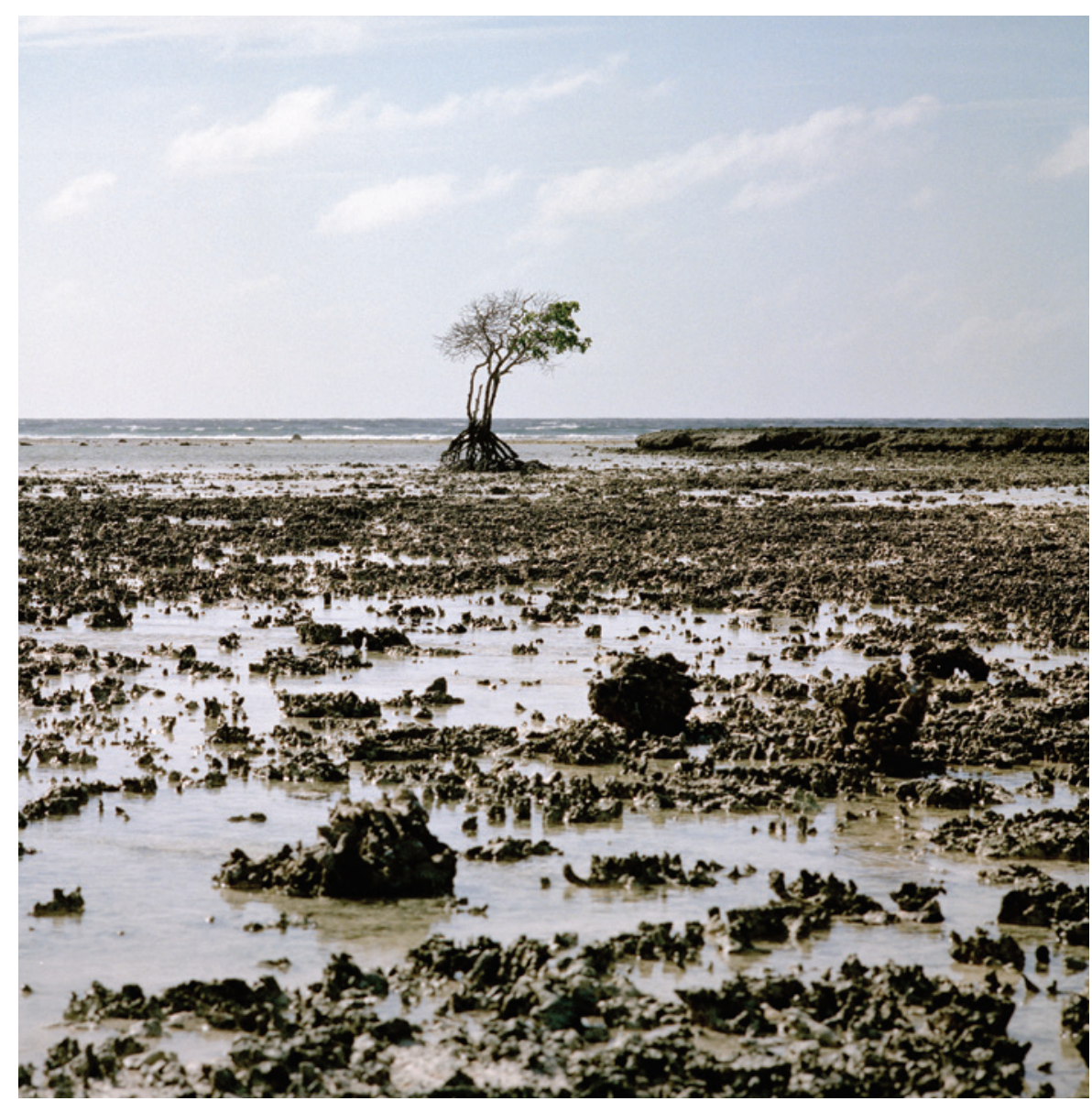

This former mangrove forest once provided benefits such as storm protection and carbon sequestration.

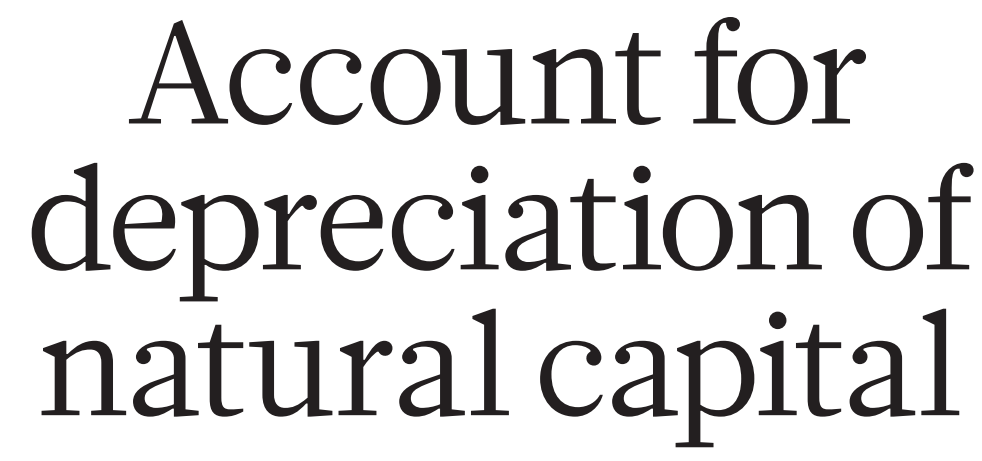

$\mathrm{F}$ or the past year, academics and policy1 makers have been discussing Thomas Piketty's 2013 economics best-seller, Capital in the Twenty-First Century ${ }^{1}$. It documents the considerable rise over the past 40 years in national wealth relative to national income in eight of the richest economies the United States, Japan, Germany, France, the United Kingdom, Italy, Canada and Australia. The national wealth of each of these countries increased from 2-3 times national income in 1970 to 4-6 times income in 2010.
Piketty relies on standard income conventions as prescribed in the United Nations national accounts. He includes natural resources such as fossil fuels, minerals and forests in his estimate of a country's capital. But his measures of national income and savings adjust only for depreciation of 'fixed capital' - buildings, equipment and so on.

We must also account for the depreciation of natural capital in appraising wealth. This is the value of net losses to natural resources, such as minerals, fossil fuels, forests and similar sources of material and energy inputs into our economy. If we use up more natural capital to produce economic output today, then we have less for production tomorrow.

At the same time, we are also squandering valuable ecological capital - ecosystems provide important goods and services to the economy, such as recreation, flood protection, nutrient uptake, erosion control, water purification and carbon sequestration. By converting and degrading ecosystems, we are depreciating this important ecological capital endowment.

Economic indicators change dramatically when the depletion and degradation of natural resources and ecosystems are accounted for. Here, I show by how much, through a worked example of mangroves in Thailand. Depreciation of natural capital is particularly high in developing economies, which are often rich in resources and ecosystems. We must retool our measures of income and wealth accordingly, starting with net domestic product.

\section{CREATIVE ACCOUNTING}

Since 1970, the World Bank's World Development Indicators have provided estimates for most countries of the adjustments to national income, income growth and savings that arise from net depletion of forests, energy resources and minerals. This rate of natural-capital depreciation as a percentage of adjusted net national income over the past four decades is alarming (see 'Natural capital').

Two global trends are noticeable. First, the decline in natural capital has been five times greater on average in developing economies than in the eight richest countries. Second, natural capital depreciation in all countries has risen significantly since the 1990s. There was a dip during the global recession of 2008-09, but as the world economy has recovered, so has the rate of resource use.

Ecological capital, too, is clearly endangered by current patterns of economic development. Over the past 50 years, ecosystems have been modified more rapidly and extensively than in any comparable period in human history, largely to meet burgeoning demands for food, fresh water, timber, fibre and fuel. According to the worldwide Millennium Ecosystem Assessment, approximately $60 \%$ of major global ecosystem services have been degraded or used unsustainably, including fresh water, wild fisheries, air and water purification, and the regulation of regional and local climate, natural hazards and pests.

Unfortunately, ecological capital, being unique, poorly understood and difficult to measure, tends to be undervalued. Consider the example of mangroves in Thailand from 1970 to $2009^{2}$. Average annual mangrove loss in Thailand has fallen steadily in every decade since the 1970s. Yet cumulatively, 
$\sim$ Thailand is estimated to have lost around 选 one-third of its mangroves since the 1970s, mainly to the expansion of shrimp farming and other coastal development.

\section{MANGROVE ECONOMICS}

Mangroves provide four essential ecosystem benefits: wood and products such as shellfish, plants, honey and medicines; nursery and breeding grounds for offshore fisheries; storm protection; and carbon sequestration.

I use estimates of these benefits to determine the annual net gain or loss in mangrove value resulting from conversion to other land uses. This net value has two components. The remaining mangroves generate extra benefits each year that do not appear in the national accounts, such as net subsistence for local coastal communities and economy-wide carbon-sequestration benefits. From these values, I subtract the net loss in land value that arises each year from converting mangroves to some other economic activity, such as shrimp farming.

The economic impacts are significant. During the 1970s and 1980s, when mangrove deforestation was rapid, Thailand lost US $\$ 1.69$ and $\$ 0.76$, respectively in mangrove net values per person per year. By 2009, around one-third of the 1970 mangrove area was deforested and Thailand's population had grown rapidly. As a result, the total value from the subsistence and carbon benefits of the remaining mangroves has halved, from $\$ 0.57$ to $\$ 0.28$ per person per year (see 'Cutting costs'). This means that even though mangrove loss slowed in the 1990s and 2000s, the net values of mangroves were very modest, only $\$ 0.11$ and $\$ 0.25$ respectively.

To put it another way, cumulative mangrove deforestation over the past four decades in Thailand has cost each Thai citizen $\$ 40$. This debit amounts to losses of more than $\$ 2.73$ billion, which have never appeared in Thailand's national accounts.

\section{COUNTING THE COST}

Many more examples are now needed for different countries and regions, and for other key ecosystems, such as tropical forests, coral reefs, freshwater wetlands, grasslands and so on.

There are three caveats. First, there are clearly intrinsic values to preserving unique natural resources, species and ecosystems, as well as the biological diversity contained in these systems, which are not captured by such an approach. Second, the benefits of many important ecosystem services are difficult to value, such as pollution control, pollination, climate regulation and watershed protection. Third, measures of natural-resource depletion need to move beyond minerals, energy and timber harvests to include other vital resources, such as soils, air quality, aquifers,

\section{NATURAL CAPITAL}

The decline in natural capital has been five times greater on average in developing economies than in the eight richest countries.

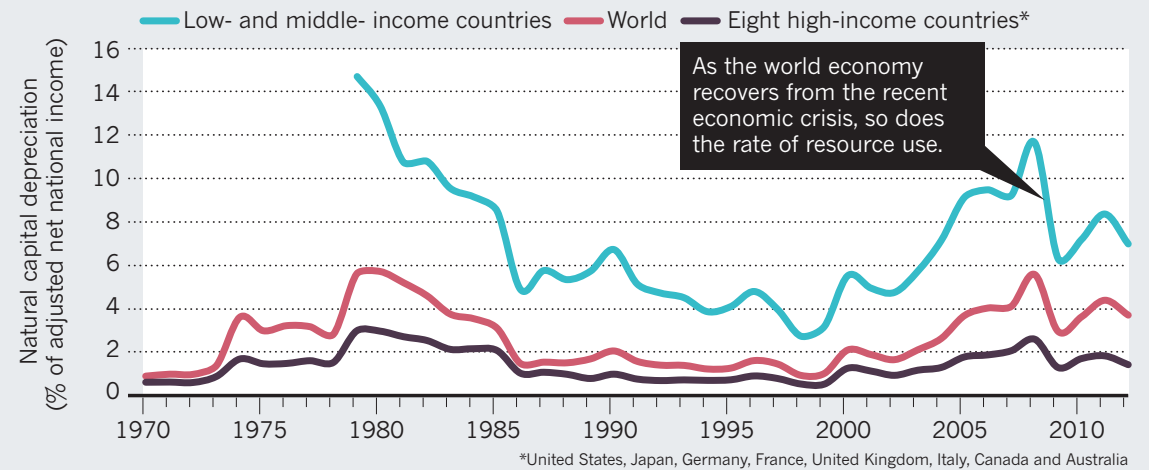

\section{CUTTING COSTS}

Losing one-third of its mangroves to deforestation since 1970 has cost Thailand more than US $\$ 2.73$ billion - a sum that has never appeared in national accounts.

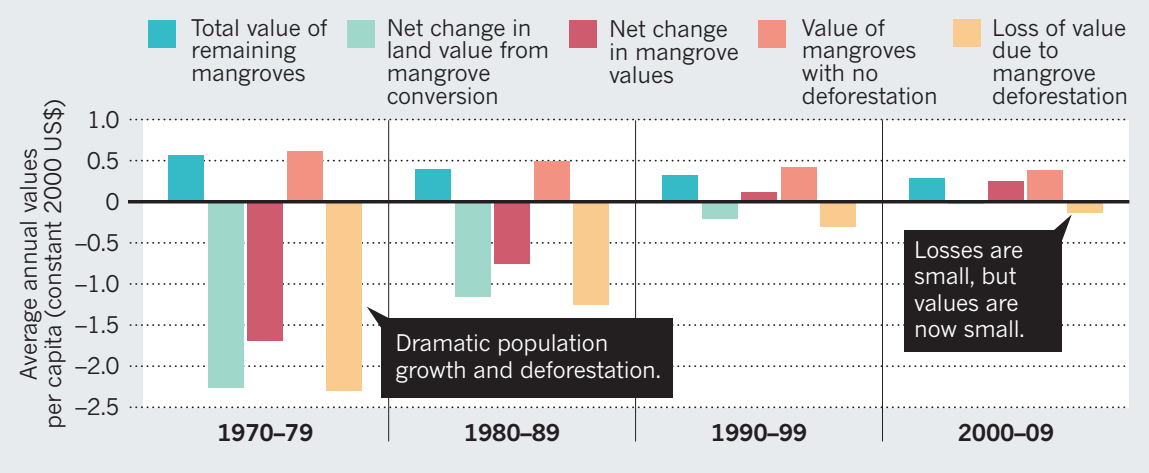

fisheries and non-timber forest resources.

The UN and the World Bank have begun pilot studies to construct adjustments to income and wealth that include changes in ecological capital. The UN Inclusive Wealth Report 2012 has developed ${ }^{3}$ accounts from 1990 to 2008 for 20 countries that include non-timber benefits from forests, carbon sequestration, fisheries (for four countries only), carbon damages and agricultural land, as well as minerals, energy and timber. The World Bank is expanding pilot studies on ecosystem accounting from 8 to 15 developing countries, which cover water, forest and mangrove ecosystems (see www.wavespartnership.org).

For estuarine and coastal ecosystems, there are already 80 valuation estimates from all over the world for storm protection, erosion control, water purification and supply, carbon sequestration, recreation and maintenance of fishing, hunting and foraging activities - and the list is growing ${ }^{4}$.

What will it take to move beyond these encouraging pilot studies? The UN systems of national accounts must adopt a more systematic approach that all countries can follow to account for losses of natural capital and ecological capital, as we already do for fixed capital depreciation. And, in the case of complex ecosystems and landscapes, we need to resolve problems of 'double counting' ecosystem services that might serve as 'inputs' into production or that are provided by multiple ecosystems, such as the protection of shorelines simultaneously by coral reefs, seagrass beds and mangroves.

Piketty might be right that, since 1970, there has been substantial accumulation of capital relative to income in the rich countries of the world. As low- and middleincome countries try to emulate this success, they will also be striving to accumulate more wealth. But as my estimates show, our economies have been trading one form of capital, Earth's riches, for another - human riches. Without accounting accurately for this trade-off, we will continue to have a false impression of economic progress and growth. That is as dangerous as flying an aeroplane into the night without navigation tools or instruments.

Edward B. Barbier is professor of economics at the University of Wyoming, Laramie, Wyoming, USA.

e-mail:ebarbier@uwyo.edu

1. Piketty, T. Capital in the Twenty-First Century (Harvard Univ. Press, 2013)

2. Barbier, E. B. Environ. Dev. Econ. 18, 133-161 (2013).

3. UNU-IHDP and UNEP Inclusive Wealth Report 2012: Measuring Progress Toward Sustainability (Cambridge Univ. Press, 2012).

4. Barbier, E. B. Resources 2, 213-230 (2013). 